\title{
DIFFERENCES IN TUBERCULAR AND CRYPTOCOCCAL MENINGITIS AS INITIAL MANIFESTATION OF AIDS
}

\author{
Mahim Mittal', Sudheer Yadav², Azhar Ali Khan ${ }^{3}$
}

1 Professor and HOD, Department of Medicine, BRD Medical College, Gorakhpur, Uttar Pradesh, India.

${ }^{2}$ Lecturer, Department of Medicine, BRD Medical College, Gorakhpur, Uttar Pradesh, India

${ }^{3}$ Associate Professor, Department of Medicine, BRD Medical College, Gorakhpur, Uttar Pradesh, India.

\begin{abstract}
\section{BACKGROUND}

Tuberculous meningitis (TBM) and cryptococcal meningitis (CCM) are among the most common CNS opportunistic infections in patients with HIV/AIDS and have a high mortality. They can be the initial manifestation of HIV infection. CCM and TBM present with a near similar clinical picture. Differentiation between these two is difficult on clinical ground. Also, basic cerebrospinal fluid (CSF) characteristics are frequently indistinguishable.

The present study was designed to observe the differences in clinical presentation and outcomes between CCM and TBM in newly diagnosed HIV patients.
\end{abstract}

\section{MATERIALS AND METHODS}

This study was a descriptive study. Patients presenting with chronic meningitis, who tested positive for HIV were included in the study. Their detailed history, physical examination, CD4 count, cerebrospinal fluid examination including India Ink preparation and Cryptococcal antigen test (CRAg) were done. CRAg was done in CSF by Cryptococcal Antigen Latex Agglutination System. Patients were treated as per standard protocols and outcome was assessed at four months. The collected data was analysed by descriptive statistical methods.

\section{RESULTS}

A total of 94 patients were studied. Out of all $45.74 \%$ cases were of TBM, 36.17\% of CCM and 18.0\% of other OI. Male to female ratio in CCM was 6: 1 and in TBM was 5.7: 1 . Mean age and CD4 count of CCM patients were $37 \pm 10.74,81 \pm 28.42$ and of TBM were $38 \pm 7.80,84 \pm 47.1$. Headache was more prevalent in CCM patients (98\%) than TBM (79\%). CSF was near normal in CCM patients. In comparison to TBM (43.3\%), mortality was higher in CCM group (56.0\%) at four months followup. Low CD4 count was associated with poor prognosis.

\section{CONCLUSION}

Meningoencephalitis is not an uncommon initial presentation in HIV/AIDS patients. TBM and CCM are the most common causes. Both have common clinical presentation, but CSF findings in CCM patients are near normal in comparison to TBM. Prognosis of both the diseases is poor in spite of full treatment, but worst in CCM.

\section{KEYWORDS}

Cerebrospinal Fluid, Cryptococcal Meningitis, Opportunistic Infection, Tubercular Meningitis.

HOW TO CITE THIS ARTICLE: Mittal M, Yadav S, Khan AA. Differences in tubercular and cryptococcal meningitis as initial manifestation of AIDS. J. Evolution Med. Dent. Sci. 2017;6(68):4868-4871, DOI: 10.14260/Jemds/2017/1055

\section{BACKGROUND}

The HIV epidemic has dramatically affected the spectrum of central nervous system disease. In HIV patients both TBM and CCM are the commonest cause of nonpyogenic meningitis. CCM and TBM present with a similar clinical picture of chronic meningitis. [1] Differentiation between these two is difficult on clinical ground. Also, basic cerebrospinal fluid (CSF) characteristics are frequently indistinguishable as both organisms classically produce a lymphocytic pleocytosis with high CSF protein levels.[2] In resource poor settings, laboratory tools are limited and confirmatory microbiological diagnosis is often not possible.

Financial or Other, Competing Interest: None.

Submission 04-08-2017, Peer Review 17-08-2017,

Acceptance 19-08-2017, Published 24-08-2017.

Corresponding Author:

Dr. Sudheer Yadav,

Lecturer, Department of Medicine.

Type-3/28, BRD Medical College Campus,

Gorakhpur, Uttar Pradesh, India.

E-mail:drsudheer05@gmail.com

DOI: $10.14260 /$ jemds $/ 2017 / 1055$
The global annual burden of cryptococcal meningitis (CCM) is estimated at 957,900 cases resulting in an estimated 624,700 deaths within 3 months of cryptococcal infection.[3] Even with antiretroviral therapy (ART) availability, CMrelated mortality remains high. ${ }^{[4]}$ Most CCM occurs in AIDS patients with advanced immunosuppression. Early diagnosis and treatment is paramount to reducing CCM-related mortality. CCM is subacute meningitis, in which the polysaccharide CRAG is detectable in serum a median of 3 weeks prior to onset of clinical symptoms. ${ }^{[5]}$ The sub-acute nature may allow for effective interventions.

Tuberculous meningitis (TBM) accounts for a substantial proportion of cases, particularly in high tuberculosis (TB) prevalence areas. Evidence shows that HIV-infected individuals are at greater risk of developing TBM, particularly at more advanced stages of immune depression[6] with mortality rates as high as $67 \% .{ }^{[7,8,9]}$ Despite treatment, mortality and long-term disability still remains unacceptably high. Thereby iterating that prevention, early recognition, diagnosis and appropriate treatment are fundamentals of improving outcome.[10] 


\section{MATERIALS AND METHODS}

\section{Study Design}

This descriptive study was conducted over a period of one academic year from September 2014 to August 2015 in the Department of Medicine, BRD Medical College and associated Nehru Chikitsalaya, Gorakhpur. Patients presenting with feature suggestive of meningoencephalitis and also tested positive for HIV were included in the study. Demographic characteristic, history of illness, clinical finding, routine investigations and CSF analysis was done for proteins, sugar, cell count, cell type, India Ink smear and cryptococcal antigen. Patient was classified as CCM on detection of the Cryptococcal antigen by CALAS or Cryptococcus demonstrated by India Ink preparation. Diagnosis of TBM was based on CSF pleocytosis and lymphocytic predominance. All CCM patients were put on amphotericin B ( $0.7 \mathrm{mg} / \mathrm{kg}$ body weight) for 2 weeks and oral fluconazole $200 \mathrm{mg}$ twice daily for 8 weeks followed by $200 \mathrm{mg}$ daily. In TBM patients, ATT started as per standard protocols. In both groups, anti-retroviral therapy was started after 2 weeks. Followup of the cases was done at 4 months. Cryptococcal antigen was demonstrated by latex agglutination test (Latex Crypto Antigen Detection System, Bharat Biologics Sciences). Patients with age less than 15 years with other opportunistic infections without CNS involvement and patients who had diabetes or any other chronic illness like chronic liver diseases, kidney diseases or other endocrinal diseases were excluded from the study.

\section{Statistical Methods}

The collected data was analysed by descriptive statistical methods. At no stage, identity of individual was disclosed. Continuous data were reported using the following descriptive statistics: number of observations (n), mean, standard deviation, minimum and maximum value. For analysing continuous data, student's t-test was carried out. Categorical data were presented using frequency (n) with percentage (\%) and comparison was done using Chi-square test. All P values for efficacy analyses were calculated at 0.05 level of significance. All statistical analyses were performed using GraphPad Prism software, Version 7.0.

\section{RESULTS}

The HIV seropositive individuals (94 cases) included in this study had the age ranging from 15 - 65 years with maximum age of presentation between $3^{\text {rd }}$ and $4^{\text {th }}$ decade $(\approx 76 \%)$. Male constitute $(85.45 \%)$ of the patients are as shown in Table 1 . Male to Female ratio in CCM group was $\approx 6: 1$ and in TBM 5.7:1. Mean age and CD 4 count in CCM patients were (37 \pm $10.74,81 \pm 28.42)$ and in TBM were $(38 \pm 7.80,84 \pm 47.1)$.

There were $18.10 \%$ of patients with $\mathrm{CD}_{4}$ count $<50$, $53.19 \%$ with CD 4 count 51 - 100, 24.46\% with CD 4 count 101 - 200 and $4.25 \%$ with CD4 count > 200, Fig. 1 . Tubercular meningitis was the most common diagnosis seen in $45.74 \%$ cases followed by cryptococcal meningitis accounts for $36.17 \%$ cases and others $18.09 \%$.

The clinical presentation of patients included fever, headache, vomiting, altered sensorium, neck stiffness, seizure and cranial nerve palsy. Headache was the common presenting symptoms in Cryptococcal meningitis (98\%). Headache was severe in intensity and situated bifrontally in CCM, whereas in TBM it was generalised. Fever was next presenting symptom in both groups. Fever was longstanding and dull in nature. Although cranial nerve involved in less number in both groups, but sixth cranial nerve was most commonly involved followed by seventh and third cranial nerve involvement, Table 2.

CSF analysis in TBM group of patients shows mean protein count and mean cell count were very high (236.78 \pm 48.86, $23 \pm 17.42$ ) in comparison to cryptococcal meningitis $(52.52 \pm 19.65,26.03 \pm 20.70)$ group of patients. CCM group of patients had near normal CSF.

Patients were treated as per standard protocols and outcome was assessed at fourth month. During hospital course 11 (30.5\%) CCM patients and 13 (30.2\%) TBM patients refused full treatment and left against medical advice and remaining 25 (69.44\%) CCM patients and 30 (69.77\%) TBM patients were discharged at 3 weeks. At the time of discharge patients in both groups regained full consciousness, well oriented to time, place and person. After 4 months, out of 25 CCM patients $14(56.0 \%)$ patients and out of 30 TBM patients 13 (43.3\%) patients expired at followup. CCM patients who died, 9 patients died within 4 weeks of discharge and 5 patients died within 12 weeks, whereas in TBM patients died within 10 weeks. The result was significant on comparison of CD4 count with outcome of discharged patients (survivor vs. non-survivor) in CCM, but not in TBM patient. The cause of death could not be ascertained in both groups, as they were out of hospital deaths (Table 3).

\begin{tabular}{|c|c|c|c|}
\hline Age (Yrs.) & Male & Female & Total (\%) \\
\hline $15-20$ & 3 & 5 & $8(8.5)$ \\
\hline $21-30$ & 32 & 5 & $37(39.36)$ \\
\hline $31-40$ & 32 & 3 & $35(37.23)$ \\
\hline $41-50$ & 11 & 1 & $12(12.7)$ \\
\hline $51-65$ & 2 & 0 & $2(2.12)$ \\
\hline Total & $\mathbf{8 0}$ & $\mathbf{1 4}$ & $\mathbf{9 4}$ \\
\hline \multicolumn{4}{|r}{ Table 1. Demography- Age and Sex Distribution } \\
\hline
\end{tabular}

\begin{tabular}{|c|c|c|c|}
\hline $\begin{array}{c}\text { Study } \\
\text { Characteristic }\end{array}$ & $\begin{array}{c}\mathrm{CCM} \\
\mathrm{N}=36\end{array}$ & $\begin{array}{c}\text { TBM } \\
\mathrm{N}=43\end{array}$ & P value \\
\hline Age in year & $37 \pm 10.74$ & $38 \pm 7.80$ & $\mathrm{NS}^{*}$ \\
\hline Male: female & $6: 1$ & $5.7: 1$ & $\mathrm{NS}^{*}$ \\
\hline Headache & 35 (97.22\%) & 34 (79.06\%) & NS* \\
\hline Vomiting & $21(58.33 \%)$ & $33(76.74 \%)$ & $\mathrm{NS}^{*}$ \\
\hline Fever & $26(72.2 \%)$ & $34(79.06 \%)$ & $\mathrm{NS}^{*}$ \\
\hline $\begin{array}{c}\text { Altered } \\
\text { sensorium }\end{array}$ & $13(36.11 \%)$ & 29 (67.44\%) & $\mathrm{NS}^{*}$ \\
\hline Neck stiffness & $12(33.3 \%)$ & $26(60.46 \%)$ & $\mathrm{NS}^{*}$ \\
\hline Seizure & $4(11.1 \%)$ & $6(13.95 \%)$ & $\mathrm{NS}^{*}$ \\
\hline CN Palsy & $5(13.9 \%)$ & $9(20.9 \%)$ & $\mathrm{NS}^{*}$ \\
\hline CSF India ink & $32(91.66 \%)$ & 0 & $\mathrm{~S}^{*}$ \\
\hline Glucose & $56.29 \pm 13.94$ & $46.07 \pm 25.91$ & $S(.0317)^{\dagger}$ \\
\hline Protein & $52.52 \pm 19.65$ & $236.78 \pm 48.87$ & $\mathrm{~S}(.0001)^{\dagger}$ \\
\hline Cell Count & $26.03 \pm 20.70$ & $140.23 \pm 17.42$ & $\mathrm{~S}(.0001)^{\dagger}$ \\
\hline Lymphocytes & $83.78 \pm 18.13$ & $75.37 \pm 22.86$ & NS $(.0780)^{\dagger}$ \\
\hline Polymorphs & $16.22 \pm 18.13$ & $24.86 \pm 22.99$ & NS $(.0714)^{\dagger}$ \\
\hline $\begin{array}{l}\text { Mortality at } 4 \\
\text { months }\end{array}$ & $14(56.0 \%)$ & $13(43.3 \%)$ & $\mathrm{NS}^{*}$ \\
\hline
\end{tabular}

$\dagger$-Student t-test

*- Chi-square test 


\begin{tabular}{|c|c|c|c|c|c|c|}
\hline \multirow{2}{*}{$\begin{array}{c}\text { Outcome at } \\
\text { Followup }\end{array}$} & \multicolumn{3}{|c|}{$\begin{array}{c}\text { CCM } \\
\text { N=25 }\end{array}$} & \multicolumn{3}{c|}{$\begin{array}{c}\text { TBM } \\
\text { N=30 }\end{array}$} \\
\cline { 2 - 7 } & $\mathbf{n}$ & CD4 Count & $\begin{array}{c}\text { P } \\
\text { value }\end{array}$ & $\mathbf{n}$ & CD4 Count & $\begin{array}{c}\text { P } \\
\text { value }\end{array}$ \\
\hline Survivor & 11 & $107 \pm 21.80$ & .0005 & 17 & $94 \pm 58.62$ & .1089 \\
\hline Non-survivor & 14 & $65 \pm 28.70$ & & 13 & $65 \pm 26.28$ & .1089 \\
\hline Table 3. Outcome of Patients at Followup \\
\hline
\end{tabular}

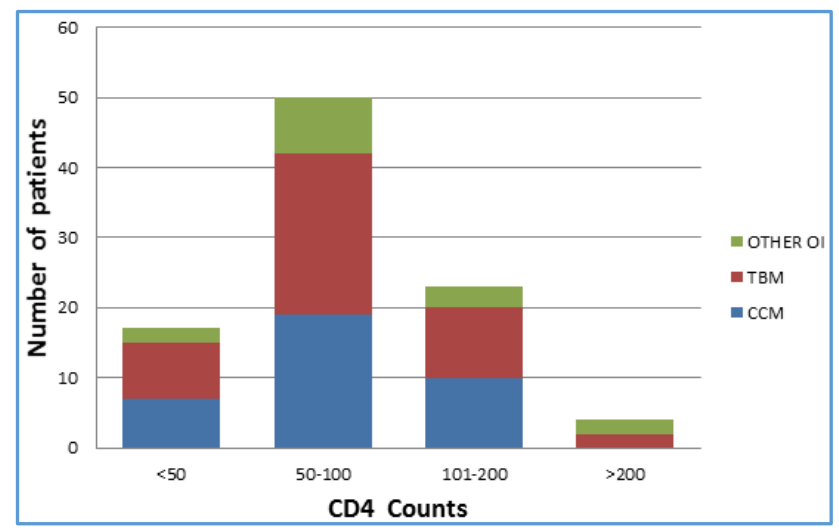

Figure 1. CD4 Count of Patients

\section{DISCUSSION}

Meningoencephalitis is not an uncommon initial presentation in HIV/AIDS. Most patients in this study presented in very late stage and their CD4 count were $<100$ cells/ $\mu \mathrm{L}$. Mean CD4 count in CCM patients is $81 \pm 28.42$ and in TBM is $84 \pm 47.1$. They were very prone to opportunistic infection. Similar finding in study of Zoseph R Zunt shows that infection of the CNS may occur during any stage of HIV infection, but opportunistic infection occurs only during late-stage infection when the $\mathrm{CD}_{4}$ count fall $<200$ cells $/ \mu \mathrm{L}_{\text {. }}{ }^{[11]}$

Aleksandra Leligowicz et al study found tubercular meningitis (TBM) to be the most common diagnosis $(25.4 \%)$ followed by acute bacterial meningitis (22.5\%), viral meningitis (14.1\%) and cryptococcal meningitis (13\%).[12] In another study Hakim et al, Zimbabwe, cryptococcal meningitis was the most common diagnosis (45\%) followed by mononuclear meningitis $(27 \%)$, acute bacterial meningitis (16\%) and TBM (12\%). In our study, tubercular meningitis was the most common diagnosis ( $45.74 \%$ cases) followed by cryptococcal meningitis (36.17\% cases) and others $(18.05 \%$ cases).

Headache was the common presenting symptoms in Cryptococcal meningitis ( 98\%), whereas in TBM group most patients presented with other symptoms as well like headache (79.06\%), fever (79\%), neck stiffness $(60.46 \%)$ and altered sensorium (67.44\%). A study from Uganda, Jacinta Oyella et al and Hakim, James G et al from Harare shows similar clinical feature. ${ }^{[13,14]}$ Although, altered sensorium and neck rigidity was seen in less number of cases of CCM, the difference was not significant.

CSF shows significant high protein $(236.78 \pm 48.86$ vs. $52.52 \pm 19.65)$, cell counts $(140.23 \pm 17.42$ vs. $26.03 \pm 20.70)$ and low sugar levels $(46.07 \mathrm{I} \pm 25.91$ vs. $56.29 \pm 13.94)$ in patients of TBM vs. CCM. These features use information which would be available in healthcare facilities with even the most basic of resources. CCM is associated with the presence of headache and low CSF white blood cell count, while TBM is associated with the presence of headache, fever, neck stiffness, high protein and cell count.

Mortality in both groups was high and significant number of patients did not continue treatment even though the medications were provided to them by hospital. The large number of defaulters make statistical interpretation difficult, but the only feature we could relate to mortality was low CD4 count in patients of CCM.

\section{CONCLUSION}

Meningoencephalitis due to the CCM or TBM is not an uncommon initial presentation in HIV/AIDS patients. Although clinical manifestations of both are nearly same, high protein and cells count favours diagnosis of TBM. Prognosis of CCM is worse than that of TBM and is related to low CD4 count. Presentation with CNS opportunistic lead to poor outcome in spite of full treatment.

\section{ACKNOWLEDGEMENT}

I extend my gratitude to all the technical and laboratory staffs of ART centre, BRD Medical College, Gorakhpur, for their cooperation and encouragement to carry out this study.

\section{REFERENCES}

[1] Schutte CM, Van der Meyden CH, Magazi DS. The impact of HIV on meningitis as seen at a south African academic hospital (1994 to 1998). Infection 2000;28(1):3-7.

[2] Heyderman RS, Gangaidzo IT, Hakim JG, et al. Cryptococcal meningitis in human immunodeficiency virus-infected patients in Harare, Zimbabwe. Clinical Infectious Diseases 1998;26(2):284-9.

[3] Park BJ, Wannemuehler KA, Marston BJ, et al. Estimation of the current global burden of cryptococcal meningitis among persons living with HIV/AIDS. AIDS 2009;23(4):525-30.

[4] Kambugu A, Meya DB, Rhein J, et al. Outcomes of cryptococcal meningitis in Uganda before and after the availability of highly active antiretroviral therapy. Clin Infect Dis 2008;46(11):1694-701.

[5] Bicanic $T$, Meintjes G, Rebe $K$, et al. Immune reconstitution inflammatory syndrome in HIVassociated cryptococcal meningitis: a prospective study. J Acquir Immune Defic Syndr 2009;51(2):1304.

[6] French N, Gray K, Watera C, et al. Cryptococcal infection in a cohort of HIV-1-infected Ugandan adults. AIDS 2002;16(7):1031-8.

[7] Micol R, Lortholary O, Sar B, et al. Prevalence, determinants of positivity, and clinical utility of cryptococcal antigenemia in Cambodian HIV-infected patients. J Acquired Immune deficiency Syndr 2007;45(5):555-9.

[8] Vinnard C, Macgregor RR. Tuberculous meningitis in HIV-infected individuals. Curr HIV/AIDS Rep 2009;6(3):139-45.

[9] Thwaites GE, Tran TH. Tuberculous meningitis: many questions, too few answers. Lancet Neurol 2005;4(3):160-70. 
[10] Torok ME, Yen NT, Chau TT, et al. Timing of initiation of antiretroviral therapy in human immunodeficiency virus (HIV)-associated tuberculous meningitis. Clinical infectious diseases 2011;52(11):1374-83.

[11] George EL, Iype T, Cherian A, et al. Predictors of mortality in patients with meningeal tuberculosis. Neurol India 2012;60(1):18-22.

[12] Brancusi F, Farrar J, Heemskerk D. Tuberculous meningitis in adults: a review of a decade of developments focusing on prognostic factors for outcome. Future Microbiol 2012;7(9):1101-16.
[13] Bergemann A, Karstaedt AS. The spectrum of meningitis in a population with high prevalence of HIV disease. QJM 1996;89(7):499-504.

[14] Hakim JG, Gangaidzo IT, Heyderman RS, et al. Impact of HIV infection on meningitis in Harare, Zimbabwe: a prospective study of 406 predominantly adult patients. AIDS 2000;14(10):1401-7. 